\title{
Hour Times Milligram per Liter per Milligram
}

National Cancer Institute

\section{Source}

National Cancer Institute. Hour Times Milligram per Liter per Milligram. NCI Thesaurus.

Code C85620.

Hours times milligrams per liter per milligram. 